Phosphorus Research Bulletin Vol. 7 (1997), 45 - 54

\title{
INHIBITION OF THE AMORPHOUS CALCIUM PHOSPHATE PHASE TRANSFORMATION REACTION BY POLYMERIC AND NON-POLYMERIC INHIBITORS
}

\section{ZAHID AMJAD \\ BFGoodrich Company, Advanced Technology Group, 9921 Brecksville Road Brecksville, Ohio 44141}

\begin{abstract}
The induction time for the transformation of amorphous calcium phosphate (ACP) to hydroxyapatite (HAP) was monitored at $\mathrm{pH} 7.40,37^{\circ} \mathrm{C}$, and calcium $=$ phosphate $=3.20 \mathrm{mM}$, in the presence of polymeric and nonpolymeric inhibitors containing various functional groups. The polymeric inhibitors evaluated include: poly(acrylic acid), molecular weight 850 to 20000 ; poly(acrylamide), PAm; poly(diallyldimethylammonium chloride), PDa; copolymers of acrylic acid:hydroxylpropyl acrylate, AA:HPA; acrylic acid:2acrylamido-2-methylpropane sulfonic acid, AA:SA; acrylic acid:vinyl acetate, AA:VAc; acrylic acid: vinyl alcohol, AA:VOH. The non-polymeric inhibitors investigated include: pyrophosphate, PYP; 1-hydroxyethylidine-1,1-diphosphonic acid, HEDP; and 2-phosphonobutane-1,2,4-tricarboxylic acid, PBTC. It was found that PAc and acrylic acid-based copolymers were effective in delaying ACP transformation reaction. The inhibitors effectiveness was greatly affected by polymer $M_{w}$ and ionic charge. For homopolymers the order in terms of decreasing effectiveness is: $\mathrm{PAc} \gg \mathrm{PAm}>\mathrm{PDa}=$ control (no inhibitor). Among copolymers, a AA:SA copolymer showed the best overall performance in terms of delaying the ACP phase transformation. For non-polymeric inhibitors, it was observed that both polyphosphate and phosphonates are potent inhibitors with HEDP more effective than PYP, as expected. The combination of PAC and PYP or HEDP or PBTC leads to a synergistic delay in the onset of the phase transformation. Reaction solutions containing 30 ppm PAc-2 ( $\left.\mathrm{M}_{\mathrm{w}} 2100\right)$ and 17 ppm HEDP resulted in a $>400 \%$ increase in induction time over what would be anticipated from an additive effect from these inhibitors.
\end{abstract}

\section{INTRODUCTION}

Dental tartar is a calcareous deposit on teeth consisting primarily of calcium phosphates and other calcium magnesium salts. The various calcium phosphate phases that may be present in the tartar include dicalcium phosphate dihydrate $\left[\mathrm{CaHPO}_{4} \cdot 2 \mathrm{H}_{2} \mathrm{O}\right]$, tricalcium phosphate $\left[\mathrm{Ca}_{3}\left(\mathrm{PO}_{4}\right)_{2}, \mathrm{TCP}\right]$, octacalcium phosphate $\left[\mathrm{Ca}_{8}\left(\mathrm{PO}_{4}\right)_{6} \cdot 5 \mathrm{H}_{2} \mathrm{O}, \mathrm{OCP}\right]$, hydroxyapatite $\left[\mathrm{Ca}_{5}\left(\mathrm{PO}_{4}\right)_{3} \mathrm{OH}, \mathrm{HAP}\right]$, and fluorapatite $\left[\mathrm{Ca}_{5}\left(\mathrm{PO}_{4}\right)_{3} \mathrm{~F}, \mathrm{FAP}\right](1,2)$. Tartar formation has been cited as a contributing factor in the 
accumulation of plaque and can adversely affect the staining of tooth surfaces by various agents (3)

It is generally agreed that initially precipitated calcium phosphate phase from aqueous solution of high supersaturation and at $\mathrm{pH}$ above 7 , is an amorphous calcium phosphate, ACP. The formation and stability of ACP phase in aqueous solution has been the subject of numerous investigations. It has been suggested that if ACP is allowed to remain in contact with the solution, it transforms to the thermodynamically stable HAP perhaps via the hydrolysis of OCP. HAP is the main component of teeth and bones.

It is well established that addition of certain compounds to a calcium phosphate supersaturated solution not only influences the kinetics of crystal growth but also affects the stability of precursor phase(s). The investigation of the influence of magnesium ion on the kinetics of crystal growth of calcium phosphates by Bachra et al. (4) and Termine et al. (5) pointed to a stabilization of ACP. Tomazic (6) and Nancollas (7) in their studies on seeded growth at lower supersaturation showed that magnesium ion induces the formation of a precursor phase rather than OCP, perhaps a mixture of OCP and DCPD. Boskey and Posner (8) reported that magnesium ion reduces the solubility of ACP, thus increasing the induction period for the transformation to HAP. Using a mixture of magnesium and Adenosine triphosphate (ATP), Blumenthal et al. showed that in the presence of these compounds the conversion of ACP to HAP is markedly delayed (9). It has also been reported that additives containing hydroxyl, carboxyl, or amino groups such as citric acid, malonic acid, benzene hexacarboxylic acid, polyglycine, etc., markedly affect the kinetics of precipitation of calcium phosphate phases $(10,11)$.

In previous publications, we showed that polymeric additives such as poly(acrylic acid), poly(maleic acid), and carboxyl containing copolymers are effective precipitation inhibitors for sparingly soluble salts such as calcium fluoride, barium sulfate, calcium sulfate, and calcium phosphates (12 - 15). This paper presents an ongoing effort to investigate the influence of a variety of polymeric inhibitors containing different functional groups such as carboxyl, amido, sulfonic, etc., on the ACP transformation reaction to HAP. Additionally, experiments have been conducted to study the influence of mixed inhibitors for possible synergistic effect on the ACP transformation reaction.

\section{EXPERIMENTAL}

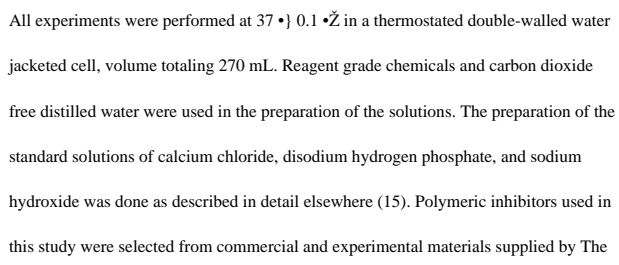


BFGoodrich Company. Phosphonates used in the present study were commercial samples received from Bayer and Monsanto Companies.

Subsaturated calcium phosphate solutions were prepared in a thermostated glass cell by adding stock solutions of calcium chloride and disodium hydrogen phosphate to the distilled water to attain initial calcium and phosphate concentrations of $3.20 \times 10^{-3} \mathrm{M}$. Experiments involving inhibitors were performed by adding the inhibitor to the subsaturated calcium phosphate solution before inducing spontaneous precipitation. Hydrogen ion measurements were made with a combination electrode equilibrated at the required temperature. The electrode was standardized for each experiment using NBS standard buffer solutions. The calcium phosphate solutions were continuously stirred with a Teflon coated stirring bar at $\sim 350$ revolutions per minute and nitrogen gas, presaturated at $37{ }^{\circ} \mathrm{C}$, was bubbled to exclude carbon dioxide from the solution. Spontaneous precipitation was induced by raising the $\mathrm{pH}$ of the solution to 7.40 with $0.10 \mathrm{M} \mathrm{NaOH}$ solution. The $\mathrm{pH}$ of the solution was maintained at $7.40 \pm 0.01$ using a Metrohm pH-stat instrument (Model 600 series, Brinkmann Instruments, Westbury, New York). The induction time at which the transformation of ACP to HAP process starts was determined as described previously

(16).

\section{RESULTS AND DISCUSSION}

Table 1 shows the structure of inhibitors used in these experiments.

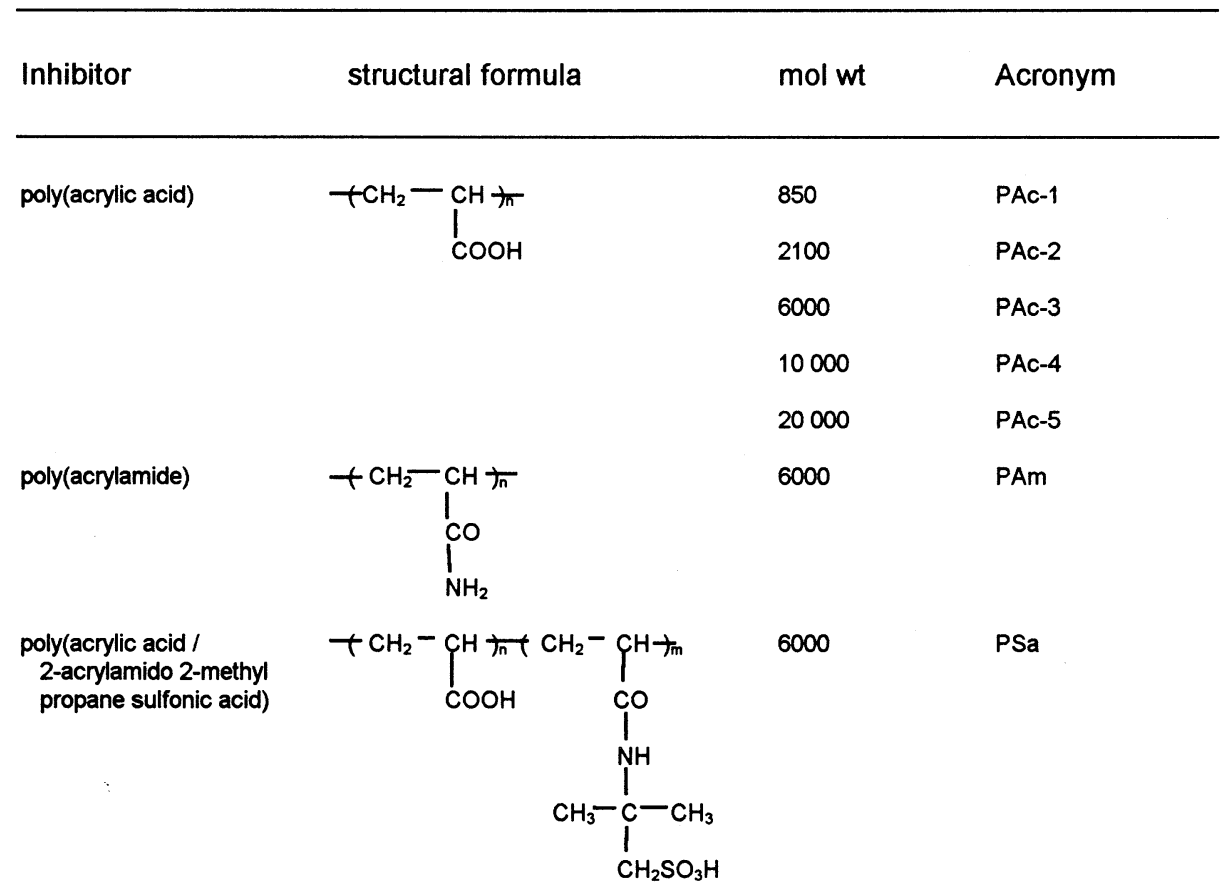


TABLE 1 . Structures of polymeric and non-polymeric inhibitors evaluated

Typical plots of the amount of $\mathrm{NaOH}$ added to the calcium phosphate solution to maintain constant $\mathrm{pH}$ are given in Figure 1.

Figure 1. $\mathrm{NaOH}$ uptake as a function of time for various inhibitors. 
The data of Figure 1 was used to determine the induction time, $\beta$, for the transformation of ACP to HAP phase. This was as determined by the dotted line in Figure 1.The influence of PAc-2 (poly(acrylic acid), molecular weight 2100) on the transformation reaction of ACP to HAP was investigated by a series of experiments summarized in Table 2. Typical examples of $\mathrm{NaOH}$ uptake - time profiles at varying concentrations of PAC-2 are illustrated in Figure 1. Curve (a) corresponds to ACP precipitation in the absence of PAc-2. As shown in curve (b), the addition of 20 ppm (parts per million) of PAC-2 to the calcium phosphate solution delays the onset of the transformation reaction. Increasing the inhibitor concentration from 20 to $55 \mathrm{ppm}$ results in approximately ten fold increase in $\beta$ and at $70 \mathrm{ppm}$ polymer concentration, ACP phase was stabilized for at least 600 minutes. It is apparent from Figure 1 that $\beta$ is greatly prolonged by increasing polymer concentration. It is interesting to note that similar observations relating to delay in ACP to HAP phase transformation have been noted in early investigations involving the influence of inhibitors such as polyphosphates, pyrophosphates, citric acid, and magnesium ion on the stabilization of ACP $(17,18)$. In addition, Amjad (19), Lieu and Nancollas (20), and Sheehan and Nancollas (21), in their studies on the precipitation of calcium sulfate, calcium phosphate, calcium oxalate, and barium sulfate, also showed that crystallization of these sparingly soluble salts is preceded by an initial slow reaction.

To determine the effect of $\mathrm{M}_{\mathrm{w}}$ (molecular weight) of PAc on the transformation reaction of ACP to HAP, the potency of poly(acrylic acids) of varying $\mathrm{Mw}_{\mathrm{w}}$ (from 850 to 20000 ) were compared as shown in Figure 2.

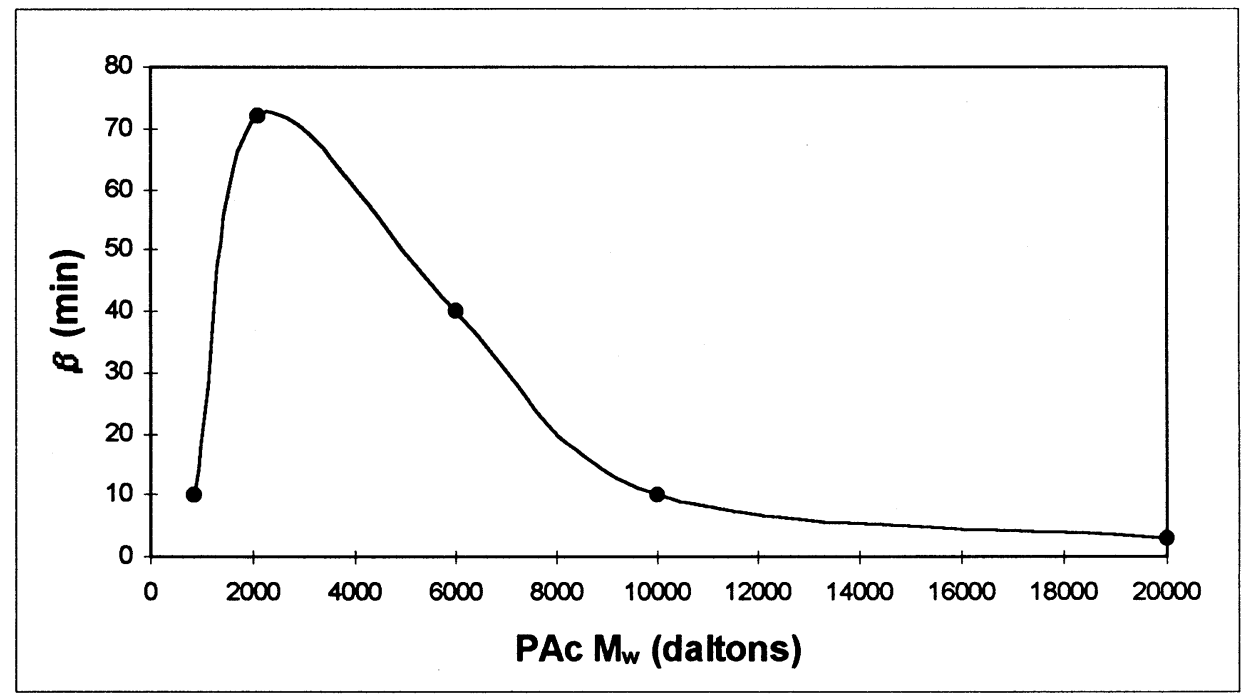

Figure 2. Induction time as a function of molecular weight of poly(acrylic acid)

The $\beta$ versus PAc $M_{W}$ profile as shown in Figure 2 clearly demonstrates that, under similar experimental conditions, inhibitory power of PAc increases with decreasing $\mathrm{M}_{\mathrm{w}}$ 
of PAc. For example, $\beta$ values obtained for PAc-2 ( $\left.M_{w} 2100\right), P A c-3\left(M_{w} 6000\right)$ and PAc-4 ( $\left.\mathrm{M}_{\mathrm{w}} 10000\right)$ are 72, 40, and 3 minutes respectively, compared to 1 minute obtained in the absence of inhibitor. It is worth noting that the effect of PAc $M_{w}$ on the stabilization of ACP phase observed in the present study is consistent with the observations made for $\mathrm{CaF}_{2}, \mathrm{CaSO}_{4} \bullet 2 \mathrm{H}_{2} \mathrm{O}$, and $\mathrm{BaSO}_{4}(13,14,22)$.

In order to investigate the role of ionic charge of the functional group (i.e., $-\mathrm{CONH}_{2}$ (neutral), $-\mathrm{SO}_{3} \mathrm{H}$ (anionic), - $\mathbf{N}$ - (cationic)) present in the polymeric inhibitor, on the precipitation and subsequent transformation into HAP, a series of experiments were carried out under similar experimental conditions. Results summarized in Table 2 and illustrated in Figure 3 clearly show that polymers which are devoid of $-\mathrm{COOH}$ group (i.e., poly(acrylamide), PAm; poly(sulfonic acid), PSa; and poly(diallyldimethyl ammmonium chloride), PDa ), exert poor inhibitory influence, compared to PAc-2, in inhibiting ACP to HAP phase transformation. Based on the $\beta$ values, the overall ranking in terms of decreasing inhibitory power of homopolymers is: PAc $>$ PSa > PAm $\sim \mathrm{PDa}$ = control (no polymer).

\begin{tabular}{|c|c|c|c|}
\hline Exp. & Inhibitor & Conc., ppm & $\beta, \min$ \\
\hline $\begin{array}{l}1 . \\
2 . \\
3 . \\
4 . \\
5 . \\
6 . \\
7 . \\
8 . \\
9 . \\
10 \\
11 . \\
12 . \\
13 . \\
14 . \\
15 . \\
16 . \\
17 . \\
18 . \\
19 . \\
20 . \\
21 . \\
22 . \\
23 . \\
24 . \\
25 .\end{array}$ & $\begin{array}{l}\text { none } \\
\text { none } \\
\text { PAC-1 } \\
\text { PAC-2 } \\
\text { PAC-2 } \\
\text { PAC-2 } \\
\text { PAC-2 } \\
\text { PAC-2 } \\
\text { PAC-2 } \\
\text { PAC-2 } \\
\text { PAC-2 } \\
\text { PAC-2 } \\
\text { PAC-3 } \\
\text { PAC-4 } \\
\text { PAC-5 } \\
\text { PAm } \\
\text { PSa } \\
\text { PDa } \\
\text { AA:HPA } \\
\text { AA:SA } \\
\text { AA:VAC } \\
\text { AA:VOH } \\
\text { PYP } \\
\text { HEDP } \\
\text { PBTC }\end{array}$ & $\begin{array}{l}-- \\
-- \\
55 \\
5 \\
10 \\
20 \\
25 \\
30 \\
30 \\
40 \\
55 \\
70 \\
55 \\
55 \\
55 \\
55 \\
55 \\
55 \\
55 \\
55 \\
55 \\
55 \\
10 \\
10 \\
10\end{array}$ & $\begin{array}{l}1 \\
1 \\
10 \\
1 \\
2 \\
7 \\
12 \\
15 \\
17 \\
28 \\
72 \\
600 \\
40 \\
10 \\
3 \\
2 \\
10 \\
3 \\
42 \\
62 \\
25 \\
14 \\
7 \\
17 \\
13\end{array}$ \\
\hline
\end{tabular}

TABLE 2. Induction times for the transformation reaction of ACP to HAP in the presence of inhibitor. 
Figure 3. Induction times of various homopolymers with differing functional

groups.

The effect of substituting sterically bulky groups onto PAc was also examined using copolymers of AA:HPA (acrylic acid : hydroxylpropyl acrylate); AA:PSa (acrylic acid: 2acrylamido-2-methyl propane sulfonic acid); AA:VAc (acrylic acid:vinyl acetate); and AA:VOH (acrylic acid:vinyl alcohol). The results summarized in Table 2 and illustrated in Figure 4, clearly indicate that inhibitory activity of the copolymer increases with the size of the steric groups. It is evident from Figure 4 that the overall ranking of these copolymers in terms of decreasing effectiveness is:

AA:PSa > AA:HPA > AA: VAc > AA:VOH. 
Inhibition of crystal growth of a number of sparingly soluble salts by PYP (pyrophosphate) has been the subject of numerous investigations. In biological calcification process, PYP ion has been found to be an effective crystal growth inhibitor for calcium oxalates and calcium phosphates systems $(15,23)$. Another class of compounds that proved to be effective in inhibiting calcification and mineral scale formation is the organic phosphonates. These inhibitors are characterized by the relatively inert $\mathrm{P}-\mathrm{C}-\mathrm{P}$ and $\mathrm{P}-\mathrm{C}-\mathrm{N}-\mathrm{C}$ bonds which substitute for the hydrolyzable $\mathrm{P}-\mathrm{O}-\mathrm{P}$ bond (Table I).

ACP precipitation experiments were carried out in the presence of various phosphorous containing compounds. Results summarized in Table 3 and shown in Figure 5 indicate that the presence of low concentrations of phosphonates lengthen the induction time. For example, the $\beta$ values obtained at $10 \mathrm{ppm}$ of PYP, HEDP, and PBTC are 7,13 , and 17 minutes, respectively. Among the phosphorous containing inhibitors the order of effectiveness as inhibitors of ACP transformation reaction is: HEDP > PBTC > PYP.

Exp. Inhibitor-I Conc., ppm Inhibitor- II Conc., ppm $\quad \beta$, min

\begin{tabular}{llllll}
\hline & & & & & \\
37. & PAC-2 & 30 & HEDP & 0 & 3 \\
35. & PAC-2 & 0 & HEDP & 10 & 17 \\
38. & PAc-2 & 30 & HEDP & 10 & 89 \\
34. & PAc-2 & 0 & PYP & 10 & 7 \\
39. & PAc-2 & 30 & PYP & 10 & 32 \\
36. & PAc-2 & 0 & PBTC & 10 & 12 \\
40. & PAC-2 & 30 & PBTC & 10 & 47 \\
\hline
\end{tabular}

TABLE 3. Induction time $(\beta)$ for phase transformation reaction of ACP to HAP in the presence of mixed inhibitors

The results of experiments to test the influence of mixed inhibitors (i.e., PAc and phosphonates) on the ACP to HAP transformation are summarized in Table 3. The data presented in Figure 5 clearly illustrate that the effect of PAC-2 plus phosphorous containing compound is to lengthen the induction time, i.e., large increase in the delay of onset conversion relative to the PAc-2 or phosphonates alone. 


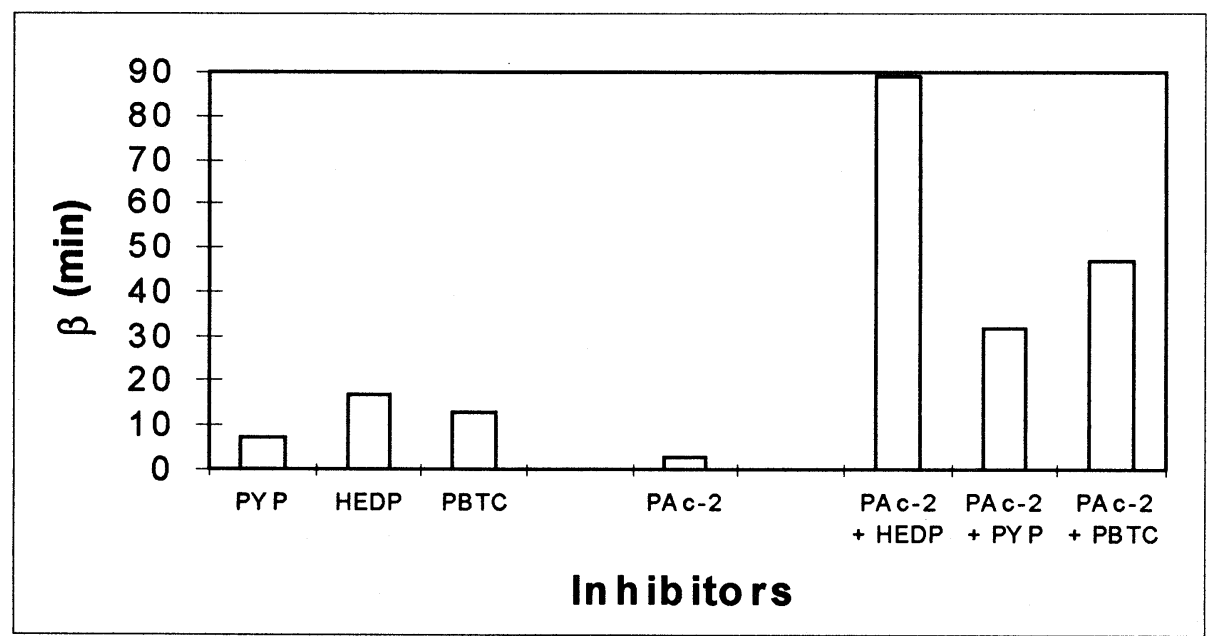

Figure 5. Induction times of various phosporus-containing compounds and blends with poly(acrylic acid).

For example, $\beta$ values obtained in the presence of $30 \mathrm{ppm}$ Pac-2 and $10 \mathrm{ppm}$ HEDP are 3 and 17 minutes respectively, compared to 89 minutes (> 400\% increase in induction time) observed in the presence of 30 ppm PAc-2 and 10 ppm HEDP. It is interesting to note that similar observation have been made in studies involving the inhibition of ACP by mixture of $\mathrm{Mg}+$ polyphosphates and $\mathrm{Mg}+$ ATP. Amjad also reported similar synergistic performance of PAA and phosphonates in the precipitation of $\mathrm{BaSO}_{4}$ and $\mathrm{CaSO}_{4} \cdot 2 \mathrm{H}_{2} \mathrm{O}(24)$. 


\section{REFERENCES}

1. G.N. Jenkins, The Physiology and Biochemistry of the Mouth, 4th ed. Blackewell Scientific

Publications, Oxford (1978)

2. M. Sundberg and J. Friskopp, Scand. J. Dent. Res. 93, 30 (1985)

3. A. Gaffar and E. Moreno, J. Dent. Res. 64, 6 (1985).

4. B.N. Bachra, O. R. Trautz, and S. L. Simon, Arch. Oral Biol. 10, 731 (1965)

5. J.D. Termine and A. S. Posner, Arch. Biochem. Biophys. 140, 307 (1970)

6. B. Tomazic, M. Tomson, and G. H. Nancollas, Arch. Oral. Biol. 20, 803 (1975)

7. G.H. Nancollas, B. Tomazic, and M. Tomson, Croat. Chem. Acta. 48, 431 (1976)

8. A.L. Boskey and A. S. Posner, Mater. Res. Bull. 9, 907 ( 1974)

9. N.C. Blumenthal, F. Betts, and A. S. Posner, Calcif. Tissue Res. 23, 245 (1977)

10. L.J. Brecevic and H. Furedi-Milhofer, Calcif. Tissue Int. 27, 131 (1979)

11. J.V. Garcia-Rames and P. Carmona, J. Cryst. Growth 57, 336 (1982)

12. Z. Amjad, Langmuir 5, 1222 (1989)

13. Z. Amjad, Langmuir 7, 2405 (1991)

14. Z. Amjad and J. Hooley, J. Colloid Interface Sci. 111, 496 (1986)

15. Z. Amjad, Langmuir 3, 1003 (1987)

16. M.J. Root, Calc. Tissue Int. 47,112 (1990)

17. M.D. Francis, Calcif. Tissue Res. 6, 335 (1971)

18. J.L. Meyer and A. H. Selinger, Mineral Electrolyte Metabol. 3, 207 (1980)

19. Z. Amjad, Colloids and Surfaces 48, 95 (1990)

20. S.T. Liu and G. H. Nancollas, J. Colloid Interface Sci. 52, 582 (1975)

21. M.E. Sheehan and G. H. Nancollas, Invest. Urol. 17, 446 (1980)

22. Z. Amjad, Water Treatment, 9, 47 (1994)

23. G.L. Gardner, J. Phys. Chem., 82, 864 (1978)

24. Z. Amjad, U. S. Patent No. 4,806,259 November 15, 1988 